\title{
EVALUATING TRAFFIC RISK INDEXES IN IRAN'S RURAL ROADS. CASE STUDY: ARDABIL-MESHKIN RURAL ROAD
}

\author{
Mazdak Sadeghpour ${ }^{1}$, Mehdi Mohammadi \\ ${ }^{1}$ Istanbul Technical University, Faculty of Urban and Regional Planning, \\ Istanbul, Turkey \\ +905395674063,Sadeghpour@itu.edu.tr \\ ${ }^{2}$ Semnan University, Faculty of Civil Engineering \\ Semnan, Iran \\ +982331533798,mmahdii@semnan.ac.ir
}

\begin{abstract}
The main objective of this study is to rank the chief parameters and their important features which lead to rural roads accidents in Iran. To conduct this, an item as Risk Index is defined as the risk of a parameter and feature causing road accidents. Of all detected parameters, only five parameters and their features were chosen. Then Analytic Hierarchy Process (AHP) was applied to find the scores of Risk Indexes of each parameter and feature to rank them with regard to the two main criteria. These criteria were "Effect on Accidents Number" and "Effect on Accident Severity". The data of this research was collected from two forms of questionnaires. Each of the 622 participants of this research filled both forms of the questionnaires. The results show that considering only Risk Index of main parameters in rural roads led to a big misunderstanding about detecting traffic accident causes. A comparison between obtained scores for both Risk Indexes of parameters and features clarifies that paying more attention to road features rather than road parameters can bring about detecting hazardous locations more accurately to assign limited budget to vulnerable locations in rural roads and decrease the rate of traffic accidents.
\end{abstract}

Keywords: rural road; traffic accidents; road parameters; road features

\section{Introduction}

There are annually more than 50 million injuries and about 1,200,000 fatalities in the world due to road traffic accidents (Peden, 2004). In Iran, the population of which is less than $1 \%$ in the world population, the rate of accidents is really high. According to the Iran's police annual reports (Shafabakhsh et al., 2012), in recent years, the number of road accident injuries is about 100000 and the number of fatalities is more than 26000; moreover, Iran's rural roads in which more than 12000 fatalities per year occurred is considered as the most severe type in comparison with other types like rural roads. A simple comparison between rate of traffic accident in Iran and other countries shows that the level of traffic safety in these countries is very higher than that in Iran (Peden, 2004; Haji Hosenloo and Aslani, 2005). Therefore, it is highly necessary to pay more attention to traffic accidents in Iran to increase the level of safety and improve the current conditions.

In Iran, on the one hand due to an apparent lack of road accident data, the security of them, as well as marked differences in the published traffic accident data by different organizations such as police and coroner offices, and on the other hand due to limited budgets and a distinct lack of identification strategies to detect road hot spots, it is irreversible to apply traditional methods in order to enhance level of rural road safety and decrease traffic accidents. In these situations, it is really unavoidable to employ new methods that are able to predict the road difficulties and deficiencies before they cause traffic accidents.

According to the previous researches (Habibian et al., 2011; Cafiso et al., 2010), there are generally four main factors that play a key role in road accidents. These four factors are "Road", "Human", "Vehicle", and "Environment". Of these four factors, only "Road" is capable of being easily improved by traffic and transportation engineers to decrease the rate of rural road accidents. Considering the fact, the main objective of this paper is to investigate and rank the chief parameters of "Road" factor and their various features. To conduct this, an item as Risk Index is defined as the risk of a parameter or a feature causing road accidents. The higher scores of Risk Index, the higher likelihood of road accidents. This approach is one of the best management procedures to control the road traffics, identify hazardous points more quickly, assign limited budget to improve these parts more properly, and finally enhance level of Iran's road level of safety. 
However, most of the previous studies done on Risk Index are only focused on some limited parameters such as "Road Alignment" regardless of paying attention to their features such as "Road Curves". These kinds of researches lead to a sharp misunderstanding about detecting and ranking the real causes of traffic accidents. In this study, first, main parameters of "Road" factor were detected and ranked, then the different features of the detected parameters were investigated and ranked as well, and finally, the relations, differences, and similarities between these two ranking were assessed.

\section{Literature review}

In previous studies, different references identified and investigated effective parameters in rural road accidents with different strategies. The base of some studies is the road accident data and establishing statistical modelling of accidents (Cafiso et al., 2010; Oh et al., 2004; Pai, 2008; Joon-Ki et al., 2008). The base of other studies is explanatory approaches due to the lake of easy accessibility to traffic accidents data or doubt on their accuracy (Habibian et al., 2011; Nassiri and Mojarad, 2006; De Leur and Sayed, 2002; Cafiso et al., 2007; European Commission, 2008; Lazim and Nurnadiah, 2010; Najib et al., 2012; Mesbah and Habibian, 2006). One of the primary kinds of the last approaches is the investigating of Risk Index (Habibian et al., 2011; Nassiri and Mojarad, 2006). There are three common methods to measure and investigate this Index. These three types are "Traffic Conflict Technique" (De Leur and Sayed, 2002), "Subjective Rating System" (Cafiso et al., 2007; European Commission, 2008; De Leur and Sayed, 2002), and "Multi Criteria Decision Making Approach" (Habibian et al., 2011; Nassiri and Mojarad, 2006; Lazim and Nurnadiah, 2010; Najib et al., 2012; Mesbah and Habibian, 2006). The concept of "Traffic Conflict Technique" was firstly presented as an alternative to traffic accident data; particularly, when there is no accurate and reliable accident data (De Leur and Sayed, 2002). The aim of this approach is to define traffic conflicts occurred frequently that led to severe road accidents. "Subjective Rating System" was initially used by Transport Road Research Laboratory in 1990 (European Commission, 2008) to identify and investigate main road parameters leading to accidents. This approach is based on obtained data from questionnaires. "Multi Criteria Decision Making Approach" mainly apply to rank the parameters of road accidents (Habibian et al., 2011; Nassiri and Mojarad, 2006; Lazim and Nurnadiah, 2010; Najib et al., 2012; Mesbah and Habibian, 2006). Nassiri and Mojarad (2006) used Simple Additive Weighting (SAW) to calculate the road Risk Index in Iran's intersection and rural roads. Furthermore, Lazim A. and Nurnadiah Z. (2010) employed Fuzzy TOPSIS to rank the parameters of traffic accidents in Malaysia. Najib L. et al. (2012) weighted and ranked the main causes of road accidents using Analytic Hierarchy Process (AHP). Mesbah and Habibian (2006) investigated the level of road safety in urban areas, extended a management approach based on AHP. Habibian et al. (2011) used AHP to rank the hazardous locations in two lane rural roads when there was no accident data.

Moreover, many researches (Habibian et al., 2011; Cafiso et al., 2010; Nassiri and Mojarad, 2006; De Leur and Sayed, 2002; European Commission, 2008; Najib et al., 2012; Mesbah and Habibian, 2006; Nodari and Lindou, 2007) have been previously done to detect the rural roads parameters and features which lead to traffic accidents. They identified more than 80 road parameters and 290 features, impacting on road safety. Summary of used parameters are shown in Table1.

Table 1. Common Rural Road Parameters Leading to Accidents Used in Previous Studies

\begin{tabular}{|l|c|l|}
\hline Researcher & No. of Parameters & Parameters \\
\hline $\begin{array}{l}\text { De Leur and Sayed, } \\
2002\end{array}$ & 6 & $\begin{array}{l}\text { "Horizontal and / or Vertical Curve", "Highway Access", "Overtaking", "Roadside } \\
\text { Hazard", "Road Surface / Super-elevation", and "Design Consistency / Expectation" }\end{array}$ \\
\hline $\begin{array}{l}\text { Nodari and Lindou, } \\
2007\end{array}$ & 9 & $\begin{array}{l}\text { "Surface Conditions", "Horizontal Curves", "Intersections", "Vertical and Horizontal } \\
\text { Signaling", "Longitudinal Elements, Cross Section", "Vulnerable Users", "Roadside", } \\
\text { and "General Elements" }\end{array}$ \\
\hline $\begin{array}{l}\text { Nassiri and Mojarad, } \\
2006\end{array}$ & 9 & $\begin{array}{l}\text { "Road Alignments", "Sight Distance", "Intersections", "Road Lighting", "Traffic } \\
\text { Capacity", "Surface Condition", "Roadside", "Lane Width", and "Pavement } \\
\text { Conditions" }\end{array}$ \\
\hline $\begin{array}{l}\text { Mesbah and Habibian, } \\
2006\end{array}$ & 5 & $\begin{array}{l}\text { "Traffic Conditions", "Road Alignments", "Road Physical Conditions", "Road } \\
\text { Control Conditions", and "General Elements" }\end{array}$ \\
\hline $\begin{array}{l}\text { European Commission, } \\
2008\end{array}$ & 6 & $\begin{array}{l}\text { "Road Alignment", "Road Junctions - Private Accesses", "Overtaking", "Roadside", } \\
\text { "Pavement and Super-elevation", and "Consistency" }\end{array}$ \\
\hline Cafiso et al., 2010 & 6 & $\begin{array}{l}\text { "Curve: bending radius", "length", "Tangent: length", "Cross section", "Density of } \\
\text { driveways", and "Roadside hazard". }\end{array}$ \\
\hline Habibian et al., 2011 & 6 & $\begin{array}{l}\text { "Straight Segments", "Horizontal and Vertical Curves", "Bridges", "Tunnels", and } \\
\text { "Merges and Intersections", and "Side Road Land Use" }\end{array}$ \\
\hline Najib et al., 2012 & 5 & $\begin{array}{l}\text { "Driving Faster than Limited Speed", "Driving Carelessly", "Adverse Road and } \\
\text { Traffic Conditions", and "Tyre and Brake Defects", and "Obstructions" }\end{array}$ \\
\hline
\end{tabular}




\section{Methodology}

To conduct this study, at first, all of the rural road parameters and features impacting on traffic accidents were investigated and selected. Of all detected parameters and features, only five important parameters and twenty features were chosen. Furthermore, to consider the role of other three main factors: "Human", "Vehicle", and "Environment", three parameters including "Drivers Violations", "Vehicles Deficiencies", and "Interaction of Vehicles and Pedestrians" were investigated as well. Three last mentioned parameters were not involved in analyzing process and just applied to calculate the accurate proportions of weights in analysis procedure. To rank the effective parameters and features leading to road accidents, three criteria including "Effect on Accident Number", "Effect on Accident Severity", and "Costs and Hardness of Iran's Road Parameters Improvement" were considered. The last criterion was not used in final analysis and only used to understand the cost of enhancing the level of traffic safety in Iran's rural roads based on experts' viewpoints.

A Multi Criteria Decision Making Approach of AHP was employed to find the score of Risk Index of each of chosen parameters and features and rank them with regard to the two main criteria of "Effect on Accidents Number" and "Effect on Accident Severity". The data of this research was collected from two forms of questionnaires. Each of the 622 Participants of this research filled two forms of questionnaires. Participants were comprised of five expert groups: (i) Police and Insurance companies, (ii) Professional Drivers, (iii) Road Organization Experts, (iv) Road Designers and (v) Students and Professors of the under-study area professional universities and organizations. In addition, all of five groups of participation of the study survey had experience working or driving on the under-study road. Finally, using obtained data from 244 answered questionnaires and with employing AHP, the Risk Index of five chosen parameters and twenty features were evaluated; then, a comparison was made between two different rankings.

\section{Forming questionnaires and data collection}

Considering previous studies (Habibian et al., 2011; Cafiso et al., 2010; Nassiri and Mojarad, 2006; De Leur and Sayed, 2002; European Commission, 2008; Najib et al., 2012; Mesbah and Habibian, 2006; Nodari and Lindou, 2007), experts viewpoints, field studies, and road auditing, five parameters related to "Road" factor that play prominent roles in rural road traffic accidents, along with twenty features related to these parameters were chosen. These parameters are "Road Alignments", "Road Junctions", "Overtaking", "Consistency", and "Road Side". According to the mentioned materials in the last section, to conduct a fully comprehensive research, three parameters of other three main factors: "Human", "Vehicle", and "Environment" were considered as well. All of the mentioned parameters and features which were used in this research are shown in Table 2.

Table 2. Eight Chosen Parameters and Features Impacting on Rural Road Accidents

\begin{tabular}{|c|c|c|}
\hline Parameter & Abbreviation & Features \\
\hline Road Alignment & $R A$ & $\begin{array}{l}\text { Curve Radius, Lane Width, Shoulder Width, Carriageway Serviceability Index, } \\
\text { Shoulder Serviceability Index, Sight Distance (Vertical and Horizontal), Traffic Signs } \\
\text { and Signals }\end{array}$ \\
\hline Road Junctions & $R J$ & Number of Junctions, Junctions Shape, Availability of Other Junction, Junction Signs \\
\hline Overtaking & OT & $\begin{array}{l}\text { Sight Distance, Overtaking Road Marking Length, Overtaking Prohibited Length, } \\
\text { Permission of Overtaking Before Left Turns, Overtaking Signs and Signals }\end{array}$ \\
\hline Consistency & $\mathrm{CO}$ & $\begin{array}{l}\text { Drivers Unexpected Reactions, Road Signs versus Drivers' Conception, Relationship } \\
\text { between Two Sequence Curves }\end{array}$ \\
\hline Roadside & $R S$ & Roadside Parameters Such as obstacles, their distances, Cut/ Fill Slopes. \\
\hline Drivers Violations & $D V$ & Driving Faster than Limited Speed, Driving Carelessly, Feeling Asleep While Driving \\
\hline Vehicles Deficiencies & $V D$ & Tire and Brake Defects, Technical Problems \\
\hline $\begin{array}{l}\text { Vehicles and } \\
\text { Pedestrians } \\
\text { Interaction }\end{array}$ & IVP & $\begin{array}{l}\text { Adverse Road and Traffic Conditions, The Role of Road Traffic and Pedestrians on } \\
\text { Road Accidents }\end{array}$ \\
\hline
\end{tabular}

The data of this study was collected using 1244 questionnaires, two 622 separate questionnaires. One of these two questionnaires, which focus only on parameters of "Road" factor, was formed in seven 
pages and twenty four questions. Another one, which focus on twenty features of five parameters, was formed in thirteen pages and sixty questions. Because these two questionnaires format was similar, just the first questionnaire's form is illustrated here. In the first page, participants are asked to write a short summery of their own previous jobs and studies. These kinds of information assist a lot in removing those samples that are not highly reliable. The main reason of the eliminating some of the questionnaires is the lack of relations of the participants' backgrounds with the goal of this research. In the second page, the eight mentioned parameters in Table 2 are introduced and the way of filling the questionnaires are explained to participants. In the next pages, five-answer-choice questions including "Highest Effect", "Good Effect", "Fair Effect", "Low Effect" and "Lowest Effect" are asked about each of the eight parameters. Moreover, in the last page, participants are asked to put a range between 1 to10 to each of three mentioned criteria. The number of 10 shows the highest effect and the number of 1 show the lowest. The process of this survey lasted for 41 days, started from August 23 to October 2 in 2014.

All of the participants of this study were experts in the transportation and traffic safety fields. To do a more accurate survey, they were classified in five groups including "Police and Insurance Companies", "Experts of Terminals and Road Organizations", "Road Designers", "Professional Drivers", and "Transportation Students and Professors". At the end of the survey, 772 questionnaires were achieved from all of the five mentioned groups which only 244 questionnaires were acceptable according to the first page information. Of these 244 questionnaires, 72 questionnaires belonged to "Police and Insurance Companies", 56 questionnaires belonged to "Experts of Terminals and Road Organizations", 34 questionnaires belonged to "Road Designers", 30 questionnaires belonged to "Professional Drivers", and 52 questionnaires belonged to "Transportation Students and Professors".

\section{Data analysis}

\subsection{Multi criteria decision making approach and AHP}

In this study, Multi-Criterion Decision Making Approaches was used to analyze the data. From the different approaches in this realm (Habibian et al., 2011; Nassiri and Mojarad, 2006; Lazim and Nurnadiah, 2010; Najib et al., 2012; Mesbah and Habibian, 2006; Mojarad, 2000; Aeashthi and Chauhan, 2011; Poh and Ang, 1999; Zhou and Chen, 2008), Analytic Hierarchy Process (AHP) (Habibian et al., 2011; Najib et al., 2012; Mesbah and Habibian, 2006) was chosen, firstly because it is frequently used in the traffic and transportation fields (Aeashthi and Chauhan, 2011; Poh and Ang, 1999; Zhou and Chen, 2008), and secondly, because it reflects the natural behaviour and human thoughts and makes the decision-maker able to present the interaction between different criteria in different and non-structural situations (Saaty, 1980). In Figure 1, the hierarchy structure of first questionnaire form, investigating the five parameters, is presented.

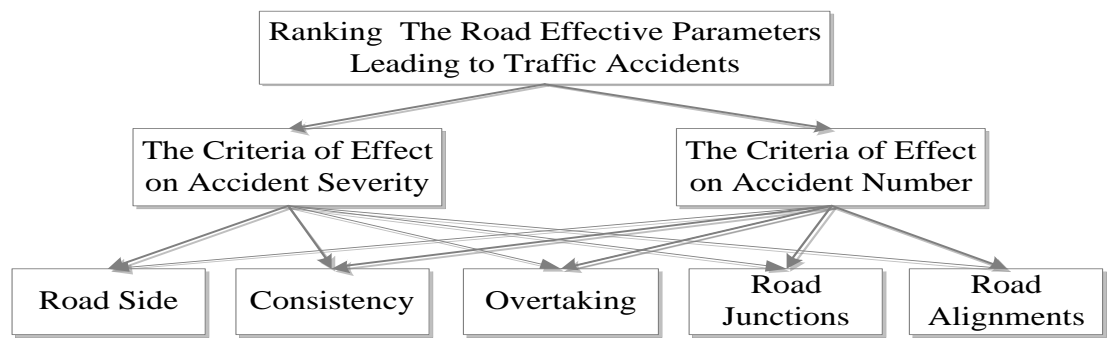

Figure 1. Hierarchy structure of road effective parameters leading to accidents

The first stage in analyzing data using AHP is to form the pair-wise comparisons matrixes. In this stage, elements of each level are compared in pairs with the elements in the higher level, and then, the pair-wise comparisons matrixes are formed. A pair-wise comparisons matrix is shown as following:

$A=\left[\begin{array}{lrrr}a_{11} a_{12} & \ldots & a_{1 n} \\ a_{21} a_{22} & \ldots & a_{2 n} \\ \ldots & \ldots & \ldots & \ldots \\ a_{n 1} a_{n 2} & \ldots & a_{n n}\end{array}\right]$,

where $a_{i j}$ is the preference of element $i$ to element $j$. In the paired comparison matrix, Equation 2 could be true because of the reversed condition: 
$a_{i j}=\frac{1}{a_{j i}}$

The pair-wise comparisons matrix is a $n \times n$ matrix in which $n$ is the number of the elements being compared.

In AHP, the elements of each level are compared to each of the elements in the higher level, and their weights are calculated. These weights are called local priority. Then, by mixing local priorities, the overall priority is determined. The weights of criteria reflect their importance in determining the goal. The weight of each alternative related to the criteria is the share of that alternative in the related criterion. Therefore, the overall priority of each alternative is calculated by multiplying the weight of each criterion in the weight of that alternative. The sum of the scores related to each alternative $\left(A_{A H P}\right.$ score $)$ is calculated using Equation 3:

$A_{A H P_{\text {Score }}}=\sum_{j=1}^{n} a_{i j} \times W_{j}(i=1,2, \ldots, m)$,

where $a_{i j}$ shows the relative importance of choice i related to the criterion $C_{j}$, and $W_{j}$ shows the importance of criterion $C_{j}$.

In this study, weight functions are calculated using arithmetic average approach. In this method, first, every element of each column of matrixes has to be normalized; in order to do this, the elements of each column are added, and each of the elements is divided by this sum.

\subsection{Results of data analysis}

As previously mentioned, two forms of questionnaire were used in this study. One questionnaire was used to collect participants' viewpoints about effective parameters of "Road" factor and another was used to find participants' viewpoints about twenty features of the parameters. Because of the fact that the analysis procedure for both of these two collected data was similar, only the analysis procedure of the first form questionnaire is mentioned. To do this, first, the explanatory data of each eight parameters achieved from questionnaires were replaced with quantitative data between 1 and 5. Then, with averaging these quantitative data, weights of each parameter and feature were obtained separately for each of the five groups of participants. Furthermore, a weight was calculated for each of the three mentioned criteria based on the last page of the questionnaires. In the end, final weights of each parameter and feature were measured using Equation 4.

$I_{j}^{k}=\sum_{i=1}^{m} W_{i}^{k} \times X_{i j}$,

where:

$I_{j}^{k}=$ Final Weights of parameter $j$ related to the responses of group $k$;

$W_{i}^{k}=$ Average weight of criterion $i$ related to the responses of group $k$;

$X_{i j}=$ Weight of parameter $j$ related to the criterion $i$;

$n=$ Number of criteria.

A sample of the obtained results for the group of "Police and Insurance Companies" with regard to collected data of first form questionnaires is shown in Table 3.

Table 3. Final Weights of the Parameters Related to the Responses of "Police and Insurance Companies"”

\begin{tabular}{|l|l|l|l|l|l|l|l|l|}
\hline \multicolumn{1}{|c|}{ Parameter } & RA & $\boldsymbol{R J}$ & $\boldsymbol{O T}$ & $\boldsymbol{C O}$ & $\boldsymbol{R S}$ & $\boldsymbol{D V}$ & $\boldsymbol{V D}$ & IVP \\
\hline Effect on Accident Number & 37.95 & 33 & 39.6 & 35.06 & 31.35 & 39.60 & 34.65 & 28.05 \\
\hline Effect on Accident Severity & 35 & 31.5 & 43.75 & 31.5 & 31.5 & 43.75 & 35 & 36.75 \\
\hline Costs and Hardness of Road Improvement & 19.25 & 13.75 & 16.5 & 14.3 & 14.30 & 17.60 & 15.13 & 13.20 \\
\hline Final Weight & 92.20 & 78.25 & 99.85 & 80.86 & 77.15 & 100.95 & 84.78 & 78 \\
\hline
\end{tabular}

* This weights extracted just from participants of Police and Insurance Companies group 
Overall and separate rankings of the eight parameters based on the sum of weights of each group, which were calculated by Equation 5, are shown in Table 4 .

$I_{j}=\sum_{i=1}^{m} I_{j}^{k}$,

where:

$I_{j}=$ Weight $j$ used to final ranking;

$I_{j}^{k}=$ Final Weight $j$ related to the responses of group $k$;

$m=$ The number of groups.

Table 4. Overall and Separate Rankings of the Parameters

\begin{tabular}{|c|c|c|c|c|c|c|c|}
\hline Parameter & $\begin{array}{l}\text { Weight } \\
\text { used to } \\
\text { final } \\
\text { ranking* }\end{array}$ & $\begin{array}{l}\text { Final } \\
\text { Rank }^{* *}\end{array}$ & $\begin{array}{l}\text { Police and } \\
\text { Insurance } \\
\text { companies } \\
\text { Rank }^{* * *}\end{array}$ & $\begin{array}{l}\text { Professional } \\
\text { Drivers } \\
\text { Rank }^{* * *}\end{array}$ & $\begin{array}{l}\text { Road } \\
\text { Organization } \\
\text { Experts } \\
\text { Rank }^{* * *}\end{array}$ & $\begin{array}{l}\text { Road } \\
\text { Designers } \\
\text { Rank }^{* * * *}\end{array}$ & $\begin{array}{l}\text { Students } \\
\text { and } \\
\text { Professors } \\
\text { Rank }^{* * * *}\end{array}$ \\
\hline$V D$ & 448.43 & 1 & 1 & 3 & 1 & 3 & 1 \\
\hline$R A$ & 436.85 & 2 & 3 & 1 & 2 & 1 & 3 \\
\hline$O T$ & 417.82 & 3 & 2 & 4 & 6 & 2 & 4 \\
\hline$I V P$ & 391.43 & 4 & 4 & 5 & 5 & 4 & 2 \\
\hline$R J$ & 370.27 & 5 & 6 & 2 & 3 & 7 & 7 \\
\hline$C O$ & 347.56 & 6 & 5 & 7 & 4 & 6 & 8 \\
\hline$D V$ & 347.45 & 7 & 7 & 6 & 8 & 5 & 5 \\
\hline$R S$ & 318.31 & 8 & 8 & 8 & 7 & 8 & 6 \\
\hline
\end{tabular}

* This weights extracted from all of participants

** This ranking extracted from all of participants

*** These rankings extracted just from mentioned participant groups

To find scores of Risk Indexes of parameters, at first, three parameters of "Drivers Violations", "Vehicles Deficiencies", and "Vehicles and Pedestrians Interaction", along with the criterion of "Costs and Hardness of Road Improvement" were discarded. The paired comparison matrix of two criteria, "Effect on Accident Number" and "Effect on Accident Severity", is shown in Table 5. Moreover, the paired comparison matrixes of five parameters of "Road" factor for both mentioned criteria are shown in Tables 6 and 7. These matrixes were formed using the data of questionnaires and applying Equations 1 to 5 .

Table 5. Paired Comparison Matrix of Two Criteria of "Effect on Accident Number" and "Effect on Accident Severity"

\begin{tabular}{|l|l|l|}
\hline Criteria & Effect on Accident Number & Effect on Accident Severity \\
\hline Effect on Accident Number & 1.00 & 1.05 \\
\hline Effect on Accident Severity & 0.96 & 1.00 \\
\hline
\end{tabular}

Table 6. Paired Comparison Matrix of Road Effective Parameters with Regard to the Criterion of "Effect on Accident Number"

\begin{tabular}{|l|l|l|l|l|l|l|}
\hline Parameters & $\boldsymbol{R A}$ & $\boldsymbol{R J}$ & $\boldsymbol{O T}$ & $\boldsymbol{C O}$ & $\boldsymbol{R S}$ & Weight $^{*}$ \\
\hline$R A$ & 1.00 & 1.21 & 1.14 & 1.35 & 1.61 & 0.25 \\
\hline$R J$ & 0.83 & 1.00 & 0.94 & 1.12 & 1.33 & 0.20 \\
\hline$O T$ & 0.88 & 1.06 & 1.00 & 1.18 & 1.41 & 0.22 \\
\hline$C O$ & 0.74 & 0.89 & 0.84 & 1.00 & 1.19 & 0.18 \\
\hline$R S$ & 0.62 & 0.75 & 0.71 & 0.84 & 1.00 & 0.15 \\
\hline
\end{tabular}

* This weight extracted from all of participants just about the Criterion of "Effect on Accident Number" 
Table 7. Paired Comparison Matrix of Road Effective Parameters with Regard to the Criterion of "Effect on Accident Severity"

\begin{tabular}{|l|l|l|l|l|l|l|}
\hline Parameters & $\boldsymbol{R A}$ & $\boldsymbol{R J}$ & $\boldsymbol{O}$ & $\boldsymbol{C O}$ & $\boldsymbol{R S}$ & Weight $^{*}$ \\
\hline$R A$ & 1.00 & 1.13 & 0.87 & 1.20 & 1.25 & 0.214 \\
\hline$R J$ & 0.89 & 1.00 & 0.77 & 1.07 & 1.11 & 0.190 \\
\hline$O T$ & 1.15 & 1.29 & 1.00 & 1.38 & 1.44 & 0.246 \\
\hline$C O$ & 0.83 & 0.94 & 0.72 & 1.00 & 1.04 & 0.178 \\
\hline$R S$ & 0.80 & 0.90 & 0.69 & 0.96 & 1.00 & 0.171 \\
\hline
\end{tabular}

* This weight extracted from all of participants just about the Criterion of "Effect on Accident Severity"

The calculated weights for five parameters including "Road Alignments", "Road Junctions", "Overtaking", "Consistency", and "Road Side" with regard to both criteria of "Effect on Accident Number" and "Effect on Accident Severity" is illustrated in Figure 2. In this Figure, all of the parameters are put in ascending order considering their weights. These orders shows the importance of each parameter which leads to traffic accidents. In order to do an accurate analysis, the comparison between each of ten parameters is separately illustrated in Figure 3.

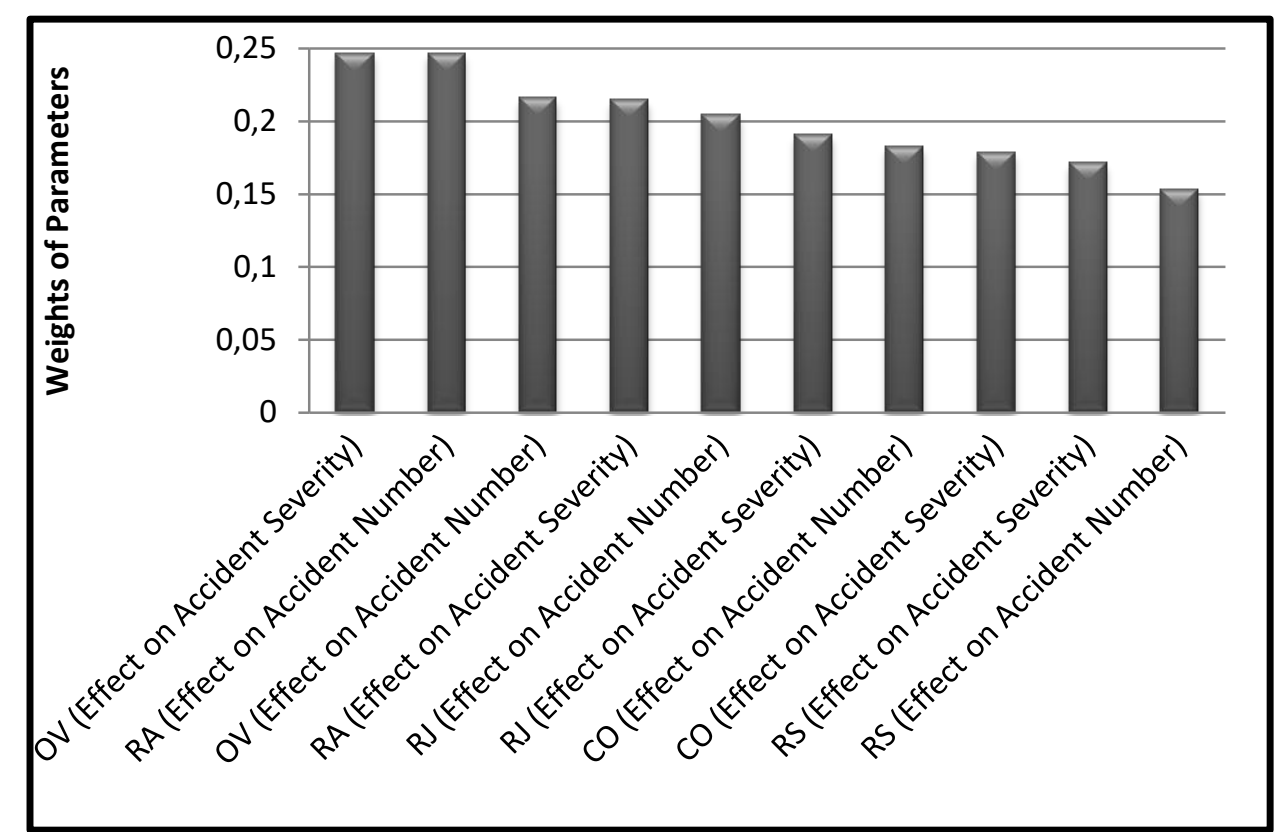

Figure 2. Weights of five parameters with regard to both criteria of "Effect on Accident Number" and "Effect on Accident Severity" based on all of participants forms

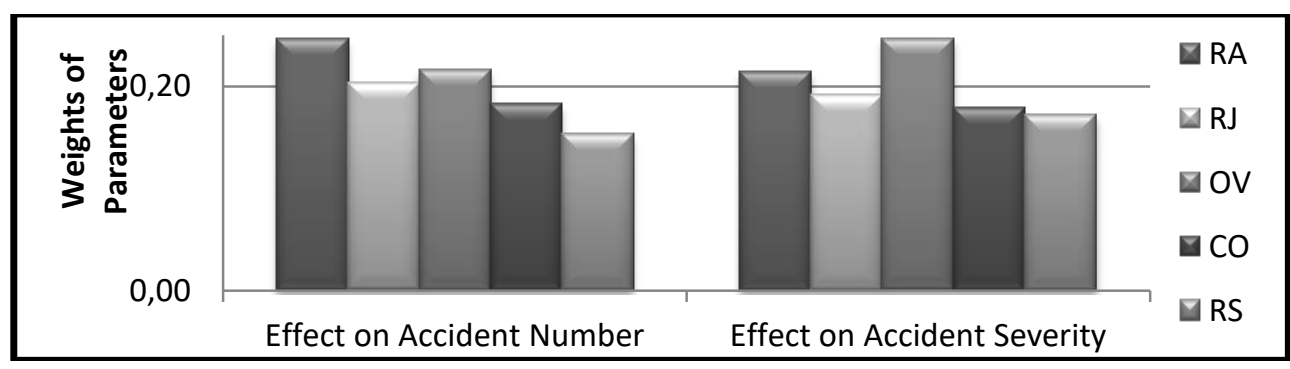

Figure 3. Comparison between weights of five parameters regarding both criteria (both based on all of participants forms)

Considering obtained weights from paired comparison matrixes of both criteria and parameters, scores of Road Risk Indexes were calculated and used to rank the five parameters. These scores are shown in Table 8. The obtained order confirms the results of previous studies done in Iran (Sadeghi and Ayati, 2013; Pouryari, 2004). 
Table 8. Scores of Road Risk Indexes and Rank of Five Detected Parameters

\begin{tabular}{|l|l|l|}
\hline Parameters & Scores of Risk Index & Rank \\
\hline Overtaking & 0.84 & 1 \\
\hline Road Alignment & 0.82 & 2 \\
\hline Road Junctions & 0.78 & 3 \\
\hline Consistency & 0.75 & 4 \\
\hline Roadside & 0.73 & 5 \\
\hline
\end{tabular}

Considering the applied procedure to analyze the collected data from first form questionnaires, the second form questionnaires data were analyzed. The final scores and ranks of the twenty features leading to rural road accidents are shown in Table 9.

Table 9. Scores of Road Risk Indexes and Rank of Twenty Detected Features

\begin{tabular}{|c|c|c|c|}
\hline Feature & Parameter & Score & Rank \\
\hline Permission of Overtaking Before Left Turns & Overtaking & 0.92 & 1 \\
\hline Overtaking Sight Distance & Overtaking & 0.89 & 2 \\
\hline Shoulder Width & Road Alignment & 0.88 & 3 \\
\hline Overtaking Prohibited Length & Overtaking & 0.81 & 4 \\
\hline Curve Radius & Road Alignment & 0.77 & 5 \\
\hline Junctions Shape & Road Junctions & 0.74 & 6 \\
\hline Relationship between Two Sequence Curves & Consistency & 0.72 & 7 \\
\hline Traffic Signs and Signals & Road Alignment & 0.63 & 8 \\
\hline Junction Signs & Road Junctions & 0.56 & 9 \\
\hline Overtaking Road Marking Length & Overtaking & 0.55 & 10 \\
\hline Drivers Unexpected Reactions & Consistency & 0.49 & 11 \\
\hline Carriageway Serviceability Index & Road Alignment & 0.46 & 12 \\
\hline Roadside Parameters Such as obstacles, their distances, Cut/ Fill Slopes. & Roadside & 0.44 & 13 \\
\hline Number of Junctions & Road Junctions & 0.38 & 14 \\
\hline Overtaking Signs and Signals & Overtaking & 0.36 & 15 \\
\hline Availability of Other Junction & Road Junctions & 0.28 & 16 \\
\hline Sight Distance (Vertical and Horizontal) & Road Alignment & 0.21 & 17 \\
\hline Road Signs versus Drivers' Conception & Consistency & 0.18 & 18 \\
\hline Lane Width & Road Alignment & 0.11 & 19 \\
\hline Shoulder Serviceability Index & Road Alignment & 0.08 & 20 \\
\hline
\end{tabular}

\section{Conclusion}

In this study, of four main factors which impact on road safety including "Road", "Human", "Vehicle", and "Environment", only the parameters of "Road" factor has been investigated because it is the only factor that can be changed and improved by traffic and transportation engineers. To do this, first, the most important five parameters of "Road" factor and twenty related features were chosen using previous studies, expert's viewpoints, field studies, and road auditing. Then, using Multi-Criteria Decision Making Approaches of AHP, the importance of each parameters and features were identified.

Two forms of questionnaires were used to collect the data of this study. One of them was associated with investigating five parameters, and another was associated with investigating twenty features of the parameters. To fill 1244 questionnaires, 622 participants, each of whom answered to two questionnaires, were classified in five different groups. Furthermore, AHP was applied to analyze the collected data and calculate the scores of each parameter and features.

The results shown the parameters of Overtaking, Road Alignment, Road Junctions, Consistency and Roadside, respectively, has more importance in Iran's rural roads accidents risk which is approved previously by other researches (Habibian et al., 2011; Lazim and Nurnadiah, 2010; Nassiri and Mojarad, 2006; Haji Hosenloo and Aslani, 2005) to a large extent. But as a very important achievement of this study, he results shows that considering only main parameters leads to a big misunderstanding about diagnosing the traffic accident problems which does not mentioned clearly in previous researches. According to the Table 8, the parameter of "Overtaking" plays the winner role and the parameter of 
"Road Side" plays the loser role in rural road accidents. However, according to the Table 9, the feature of "Overtaking Signs and Signals" related to parameter of "Overtaking" has lower rank than the features of parameter of "Road Side". Therefore, it is important to consider the features rather than parameters in order to find the rural road problems and assign limited budget to enhance their level of safety. Furthermore, with regard to the rank of parameters in Table 8 and order of highlighted parameters in Table 9, it is discovered that the importance of the five parameters in both kinds of ranking is the same. It is realized that participants while answering questions of each parameters thought about some certain features of a parameter instead of considering all features. This fact shows that paying attention merely to road parameters will result in a vague understanding about accidents causes.

According to the scores of Risk Indexes of twenty features, a new rank for features of each five detected parameters is proposed in Table 10.

Table 10. Ranking of Features of Each Five Main Parameters Leading to Rural Road Accidents

\begin{tabular}{|c|c|c|}
\hline Parameter & Feature & Rank \\
\hline \multirow{5}{*}{ Overtaking } & Permission of Overtaking Before Left Turns & 1 \\
\hline & Sight Distance & 2 \\
\hline & Overtaking Prohibited Length & 3 \\
\hline & Overtaking Road Marking Length & 4 \\
\hline & Overtaking Signs and Signals & 5 \\
\hline \multirow{7}{*}{ Road Alignment } & Shoulder Width & 1 \\
\hline & Curve Radius & 2 \\
\hline & Traffic Signs and Signals & 3 \\
\hline & Carriageway Serviceability Index & 4 \\
\hline & Sight Distance (Vertical and Horizontal) & 5 \\
\hline & Lane Width & 6 \\
\hline & Shoulder Serviceability Index & 7 \\
\hline \multirow{4}{*}{ Road Junctions } & Junctions Shape & 1 \\
\hline & Junction Signs & 2 \\
\hline & Number of Junctions & 3 \\
\hline & Availability of Other Junction & 4 \\
\hline \multirow{3}{*}{ Consistency } & Relationship between Two Sequence Curves & 1 \\
\hline & Drivers Unexpected Reactions & 2 \\
\hline & Road Signs versus Drivers' Conception & 3 \\
\hline Roadside & Roadside Parameters Such as obstacles, and their distances & - \\
\hline
\end{tabular}

Based on this rank, it is capable of being more preferable to consider some first features of each parameters to improve the traffic safety level. The used approach in this study shows that considering the effective features, leading to rural road accidents, can be applied to outline comprehensive and accurate plans for safety condition of current rural roads. For instance, when there is a limited budget, employing mentioned procedure can be firstly useful to detect hazardous locations more quickly, secondly, diagnose the difficulties of these locations more in detail, and finally be helpful to assign the limited budget to improve road problems and decrease the accidents numbers and severities.

\section{Acknowledgements}

The authors would like to thanks "Applied Research Office of Ardabil Police" to their support and assistance of accomplishing this study.

\section{References}

1. Aeashthi, A. and Chauhan, S. (2011) Using AHP and Dempster-Shafer theory for evaluating sustainable transport solutions, Environmental Modelling and Software, 787-796.

2. Cafiso, S., Graziano, A.D., Silvestro, G.D., Cava, G.L. and Persaud, B. (2010) Development of Comprehensive Accident Models for Two-Lane Rural Highways Using Exposure, Geometry, Consistency and Context Variables, Accident Analysis and Prevention, 1072-1079. 
3. Cafiso, S., Cava, G. and Montella, A. (2007) Safety Index for Evaluation of Two-Lane Rural Highway. Transportation Research Record, Journal of the Transportation Research Board. Washington, D.C. National Research Council, Vol. No. 870.

4. De Leur, P. and Sayed, T. (2002) Development of a Road Safety Risk Index, Journal of the Transportation Research Board, No. 1784, pp.33-42. - Washington, D.C. National Research Council.

5. European Commission (2008) Transport, European Commission. Ranking for European Road Safety, Specific Targeted Research or Innovative Project, 2008. - May 18, 2015. http://ec.europa.eu/transport/roadsafety/infrastructure/safety_mgnt_en.htm.

6. Habibian, M., Mesbah, M. and Sobhani, A. (2011) Ranking of Hazardous Road Locations in TwoLane Two-Way Rural Roads with No Crash Record, Australasian Transport Research Forum Proceedings, Adelaide, Australia.

7. Haji Hosenloo, M. and Aslani, N. (2005) Identification of Potential Risks in Iran Roads Based on Drivers' Offensives, The First International Traffic Accident Conference. Tehran, Iran : University of Tehran.

8. Joon-Ki, K., Gudmundue, F.U., Venky, N.S. and Mannering, F.L. (2008) Unobserved Heterogeneity and Heteroskedasticity Due to Age When Modelling Pedestrian Injury Severity in Motor Vehicle Crashes, 87th Annual Meeting of the Transportation Research Board. Washington, D.C: Transportation Research Board.

9. Lazim, A. and Nurnadiah, Z. (2010) Ranking of the Factors Associated with Road Accidents using Correlation Analysis and Fuzzy TOPSIS, Australian Journal of Basic and Applied Sciences. 2010. 2: 314-320. : Vol. 4.

10. Mesbah, M. and Habibian, M. (2006) An approach for safety assessment of urban transportation networks, 7th International Congress on Civil Engineering. Tehran, Iran.

11. Mojarad, M.M. (2000) Evaluating Risk Indexes Equations in Iran's Roads. Tehran, Iran. M.Sc. Thesis of Highway Engineering., Sharif University of Technology.

12. Najib, L., Abdullah, L., Abdullah, I. and Salleh, Z. (2012) Weights of Road Accident Causes using Analytic Hierarchy Process, ARPN Journal of Science and Technology, 2012. - 2 : Vol. 2.

13. Nassiri, H. and Moshfeghe Mojarad, M. (2006) Evaluating Hazardous Index in Iran's Urban Intersections and Rural Roads, Scientific Research Journal of Sharif. - Tehran : Sharif University of Technology, 2006. - Vol. 35.

14. Nodari, T. C. and Lindou, A. L. (2007) Proactive Method for Safety Evaluation of Two-Lane Rural Highway Segments. Transportation Research Record: Journal of the Transportation Research Board. - Washington, D.C. National Research Council. - 340.

15. Oh, J., Washington, P. and Choi, K. (2004) Development of accident prediction models for rural highway intersections. Transportation Research Record, an International Journal. Transportation Research Board, 2004. - Vol. 1897, PP 18-27.

16. Pai, C. (2008) Exploring Motorcyclist Injury Severity in Approach-Turn Collisions at T-Junctions: Focusing on the Effects of Driver's Failure to Yield and Junction Control Measures. Accident Analysis and Prevention, 40 (2), pp. 479-486.

17. Peden, M. (2004) World Report on Road Traffic Injury Prevention, Developing Countries. World Health Organization.

18. Poh, K. L. and Ang, B.W. (1999) Transportation fuels and policy for Singapore: an AHP planning approach, Computers and Industrial Engineering, 507-525.

19. Pouryari, M. (2004) Developing Safety Index Model for Iran's Road. Tehran, Iran : M.Sc. Thesis of Highway Engineering., Sharif University of Technology.

20. Saaty, T. L. (1980) The Analytic Hierarchy Process, NewYork : McGraw Hill.

21. Sadeghi, A. and Ayati, E. (2013) Application of Hazard Index for Identifying of Accident Prone Sections Based on Road Safety Inspection, The 12th International Conference on Traffic and Transportation engineering. Tehran, Iran.

22. Shafabakhsh, Gh., Mohammadi, M. and Mirzanamadi, R. (2012) An Increase in Drivers' Awareness by Separate Tail and Brake Lamp Colors, 3rd International Traffic Accident Conference, Tehran, Iran, Faculty of Engineering, University of Tehran.

23. Zhou, Z. and Chen, S. (2008) Application of DEA and AHP method in transportation mode selection, IEEE International Conference on Grey Systems and Intelligent Services. Nanjing: IEEE,1330-1333. 